\title{
Echographic evaluation of optic nerve sheath diameter in malarial patients
}

\author{
Maddalena De Bernardo ${ }^{1}$ (D . Livio Vitiello ${ }^{1}$. Nicola Rosa ${ }^{1}$
}

Received: 18 March 2019 / Accepted: 20 April 2019 / Published online: 30 April 2019

(c) Società Italiana di Ultrasonologia in Medicina e Biologia (SIUMB) 2019

Keywords Blooming effect $\cdot$ Malaria $\cdot$ Optic nerve sheath diameter $\cdot$ Ultrasound

To the Editor,

We read with great interest the noteworthy review by Malerba et al. concerning the utility of bedside ultrasound in patients with malaria [1]. We consider it a really interesting paper, but we would like to comment some aspects of optic nerve sheath diameter (ONSD) appraisal with ultrasound.

In their review, the authors highlighted the usefulness of ultrasound in evaluating several organ systems in malarial patients, including ONSD too. For this purpose, in the articles reviewed and cited by the authors, ultrasound B scan technique was utilized. This method has been employed for more than 50 years to identify several ocular and orbital diseases, but for measurements of small structures, such as ONSD, it has been proven to be quite unreliable due to the so-called blooming effect [2]. The absence of a standard gain setting in performing the examination causes this effect, meaning that, decreasing the gain, the ONSD will appear enlarged.

However, this effect could be irrelevant when large structures need to be evaluated, but this will be very significant in case of lesions inferior to $0.5 \mathrm{~mm}$, where also few microns could be influent, as for ONSD assessment.

For this reason, to overcome the aforementioned drawbacks, we would like to point out the effectiveness of Standardized A Scan, a blooming effect-free ultrasound technique that displays easily noticeable high spikes from the interface between arachnoid and subarachnoidal fluid, making these measurements objective and exacter, giving more accurate and universal reference range values [3].

Maddalena De Bernardo

mdebernardo@unisa.it

1 Department of Medicine, Surgery and Dentistry, "Scuola Medica Salernitana", University of Salerno, Via S. Allende,

Baronissi, 84081 Salerno, Italy
Lastly, A scan examination also permits to perform the "30 degrees test", which allows us to discriminate between an ONSD increase caused by raised intracranial pressure related to increased subarachnoidal fluid, and that one associated with other diseases, such as optic nerve meningioma or optic neuritis $[4,5]$.

\section{Compliance with ethical standards}

Conflict of interest The authors declare that they have no conflict of interest.

\section{References}

1. Malerba P, Kaminstein D, Brunetti E, Manciulli T (2019) Is there a role for bedside ultrasound in malaria? A survey of the literature. J Ultrasound. https://doi.org/10.1007/s40477-019-00371-8

2. Iaconetta G, De Bernardo M, Rosa N (2017) Coronal axis measurement of the optic nerve sheath diameter. J Ultrasound Med 36:1073. https://doi.org/10.1002/jum.14198

3. De Bernardo M, Rosa N (2018) Measuring optic nerve sheath diameter as a proxy for intracranial pressure. JAMA Ophthalmol 136:1309-1310. https://doi.org/10.1001/jamaophtha lmol.2018.3429

4. Rosa N, De Bernardo M (2017) Ultrasound assessment of optic nerve sheath diameter in healthy volunteers. J Crit Care 40:279. https://doi.org/10.1016/j.jcrc.2017.03.018

5. De Bernardo M, Rosa N (2017) Clarification on using ultrasonography to detect intracranial pressure. JAMA Ophthalmol 135:1004-1005. https://doi.org/10.1001/jamaophtha lmol.2017.2597

Publisher's Note Springer Nature remains neutral with regard to jurisdictional claims in published maps and institutional affiliations. 